\title{
Associations of Occupational Tasks with Knee and Hip Osteoarthritis: The Johnston County Osteoarthritis Project
}

\author{
KELLI D. ALLEN, PhD, JIU-CHIUAN CHEN, MD, ScD, LEIGH F. CALLAHAN, PhD, YVONNE \\ M. GOLIGHTLY, PT, MS, CHARLES G. HELMICK, MD, JORDAN B. RENNER, MD, and \\ JOANNE M. JORDAN, MD, MPH \\ Health Services Research and Development Service, Durham Veterans Affairs Medical Center; \\ the Department of Medicine, Division of General Internal Medicine, Duke University Medical \\ Center, Durham; Thurston Arthritis Research Center and the Departments of Medicine, \\ Orthopaedics, Social Medicine, Epidemiology, and Radiology, University of North Carolina, \\ Chapel Hill, North Carolina; Department of Preventive Medicine, University of Southern California \\ Keck School of Medicine, Los Angeles, California; and the Centers for Disease Control and \\ Prevention, Atlanta, Georgia, USA
}

\begin{abstract}
Objective-This cross-sectional study examined associations of occupational tasks with radiographic and symptomatic osteoarthritis $(\mathrm{OA})$ in a community-based sample.

Methods-Participants from the Johnston County Osteoarthritis Project $(n=2729)$ self-reported the frequency of performing 10 specific occupational tasks at the longest job ever held (never/ seldom/sometimes vs often/always) and lifetime exposure to jobs that required spending $>50 \%$ of their time doing 5 specific tasks or lifting 22, 44, or 110 pounds 10 times weekly. Multivariable logistic regression models examined associations of each occupational task separately with radiographic and symptomatic knee and hip OA, controlling for age, race, gender, body mass index, prior knee or hip injury, and smoking.
\end{abstract}

Results-Radiographic hip and knee OA were not significantly associated with any occupational tasks, but several occupational tasks were associated with increased odds of both symptomatic knee and hip OA: lifting > 10 pounds, crawling, and doing heavy work while standing (OR 1.42.1). More occupational walking and standing and less sitting were also associated with

The Journal of Rheumatology Copyright @ 2010 . All rights reserved.

Address correspondence to: Dr. K.D. Allen, HSR\&D (152), VA Medical Center, 508 Fulton St., Durham, NC 27705, USA. kelli.allen@duke.edu.

K.D. Allen, PhD, Assistant Research Professor, Health Services Research and Development Service, Durham Veterans Affairs Medical Center, and Department of Medicine, Division of General Internal Medicine, Duke University Medical Center; Y.M. Golightly, PT, MS, Research Physical Therapist, Health Services Research and Development Service, Durham Veterans Affairs Medical Center, and Doctoral Student, Department of Epidemiology, University of North Carolina; J-C. Chen, MD, ScD, Associate Professor, Department of Preventive Medicine, University of Southern California Keck School of Medicine; L.F. Callahan, PhD, Associate Professor, Thurston Arthritis Research Center and the Departments of Medicine, Orthopaedics, and Social Medicine, University of North Carolina; J.B. Renner, MD, Professor, Thurston Arthritis Research Center and the Department of Radiology, University of North Carolina; J.M. Jordan, MD, MPH, Professor, Thurston Arthritis Research Center and the Departments of Medicine and Orthopaedics, University of North Carolina; C.G. Helmick, MD, Medical Epidemiologist, Centers for Disease Control and Prevention.

The findings and conclusions in this report are those of the authors and do not necessarily represent the official position of the Centers for Disease Control and Prevention or the Department of Veterans Affairs. 
symptomatic knee $\mathrm{OA}$, and more bending/twisting/reaching was associated with symptomatic hip OA. Exposure to a greater number of physically demanding occupational tasks at the longest job was associated with greater odds of both symptomatic knee and hip OA.

Conclusion-Our results confirm an association of physically demanding occupational tasks with both symptomatic knee and hip OA, including several specific activities that increased the odds of OA in both joint groups. These tasks represent possibilities for identifying and targeting at-risk individuals with preventive interventions.

\section{Key Indexing Terms}

OSTEOARTHRITIS; OCCUPATIONS; HIP; KNEE

There are a few known modifiable risk factors for osteoarthritis (OA). Understanding these factors is critical for preventive efforts. In addition to overweight and joint injury, which are both associated with increased risk for lower extremity $\mathrm{OA}^{1}$, another potentially important factor is exposure to physically demanding occupational tasks ${ }^{2}$. In research, evidence for an association between occupational activities and OA has been strongest for the knee ${ }^{3}$. Specifically, studies have shown greater odds of both radiographic and symptomatic knee OA among individuals with overall physically demanding jobs, as well as with some specific occupational tasks, particularly knee-bending ${ }^{3-7}$. A number of studies have shown moderate associations with radiographic and symptomatic hip OA with specific occupations, especially farming, as well as with greater overall physical demands of work ${ }^{8-13}$. There has been less research examining associations of specific occupational tasks with hip OA, but some studies indicate stair-climbing and heavy lifting are associated with hip $\mathrm{OA}^{12-16}$.

Our purpose was to examine associations of occupational physical demands with lower extremity OA in the Johnston County Osteoarthritis Project (JoCo OA). These analyses are intended to augment prior knowledge regarding associations between occupation and $\mathrm{OA}$ in 3 key ways. First, we included several different types of occupational variables, including broad occupational categories, specific tasks performed at participants' longest job, and lifetime exposure to specific occupational tasks. This can provide more detail about the types of occupational variables most strongly associated with lower extremity OA, data that may direct future epidemiological work, methods, and interventions. Second, we separately examined associations of occupational variables with knee and hip OA, to add to the relatively small body of literature for hip OA. Third, we separately examined associations of occupational variables with radiographic and symptomatic OA. This is important because factors associated with radiographic versus symptomatic OA may differ, and symptomatic $\mathrm{OA}$ is of primary relevance from the perspectives of public health and clinical/health services. In addition, we included information on household tasks as covariates; these have typically not been examined in this context.

\section{MATERIALS AND METHODS}

\section{Subjects}

This cross-sectional sample was composed of individuals enrolled in JoCo OA, an ongoing community-based study of the occurrence of knee and hip OA in a rural region of the state 
of North Carolina, USA. Details of this study, including sampling strategies and recruitment methods, have been reported ${ }^{17}$. JoCo OA involved civilian, noninstitutionalized Caucasian and African American adults aged 45 years and older who resided in 6 townships in Johnston County, North Carolina. Households in these townships were visited to gather information about the demographic characteristics of the residents and invite participation of those who were eligible. At baseline (1991-1997), participants were recruited with oversampling of African Americans and undersampling of women age 65 years and older to provide adequate sample sizes for domains of interest (i.e., racial and ethnic differences). Our analysis used data collected from individuals who had participated in either the first followup of the study $(\mathrm{n}=1733)$ in 1999-2004, or the new enrollment $(\mathrm{n}=1015)$ in 20032004 (total 2748; see Figure 1). The new enrollment aimed to enrich the sample for African Americans and younger individuals. Therefore the newly enrolled participants were younger (mean age 59.3 vs 65.8 years) and more likely to be African American (40\% vs 28\%) than the participants of the first followup study; the 2 groups did not differ according to gender. Compared with the sample who participated in baseline assessments (1991-1997), the followup sample (1999-2004) comprised a higher proportion of females (65\% vs 61\%) and Caucasians ( $71 \%$ vs $68 \%)$.

Figure 1 shows participants who were included in analyses involving specific outcomes of radiographic and symptomatic knee and hip OA. Among participants who did not have hip radiographs, most were women under age 50 who did not receive hip radiographs in this study by protocol; other reasons included exceeding the weight limit for the radiograph table and bilateral hip arthroplasty. Among those who did not have knee radiographs, reasons included knee arthroplasty and inability to stand on their own for the radiograph. For both hip and knee radiographs, there were very few participant refusals. Symptom data were missing due to participant nonresponse on these items.

\section{Outcomes}

Participants underwent posterior-anterior radiography of both knees with weight-bearing using a Synaflexer ${ }^{\mathrm{TM}}$ lower limb positioning frame (Synarc, San Francisco, CA, USA). Supine anteroposterior pelvis radiographs were obtained on all men and women 50 years of age and older (because of potential reproductive issues among younger women). All radiographs were read for Kellgren-Lawrence (K-L) score by a single bone and joint radiologist without regard to the participant's clinical status or occupational activities. Interrater and intrarater reliability of the radiologist were high (weighted $\kappa=0.9$ ), as reported17. Radiographic knee and hip OA were defined as a K-L grade of at least 2 in at least 1 knee or hip, respectively.

We examined radiographic hip and knee OA as outcomes, irrespective of symptoms. Our primary outcomes for these analyses were symptomatic hip and knee OA (whether unilateral or bilateral), since symptomatic disease is of clinical and public health relevance. To assess joint symptoms, participants were asked: "On most days, do you have pain, aching, or stiffness in your...right/left knee/hip?". We defined symptomatic knee and hip OA as the presence of both radiographic OA and symptoms in the same joint. 


\section{Occupational exposure variables}

Using interviewer-administered questionnaires, we asked the participants to recall occupational exposure information. The items included in these analyses were adapted from previous population-based and clinic/community-based studies of occupational demands and knee and hip $\mathrm{OA}^{12,18,19}$.

Participants were first asked, "Have you ever held a job outside the home or farm for pay for more than 1 year?". Participants who responded "No," or that they only did homemaking and/or farming (not outside the home), were excluded from these analyses. This included 19 who farmed at home, 60 who did homemaking, 22 who did both farming at home and homemaking, and 39 who did neither. Participants who responded "Yes" were asked to report general features of the main job they held longest during their life, including the job title, age at employment inception and termination, and the length of tenure (in years). Based on the 1990 Census of Population and Housing Alphabetical Index of Industries and Occupations ${ }^{20}$, the occupational class of participants' longest job was classified into 1 of 6 industrial groups: managerial and professional specialty; technical, sales, and administrative support; service; farming, forestry, and fishing; precision production, craft, and repair; and operators, fabricators, and laborers.

Participants were also asked about performance of these tasks during the longest job they held: walking; lifting/carrying/moving objects weighing > 10 pounds; sitting; standing; bending/twisting/reaching; squatting; climbing stairs; crawling on knees; crouching or kneeling; and doing heavy work while standing. The frequency of each of these 10 physical tasks was rated on a 5 -point scale, with $0=$ never and $4=$ always, and participants were classified as exposed to the indicated physical task during the longest job if they performed these tasks often or always and as nonexposed if they reported otherwise (never/seldom/ sometimes). To assess the potential effect jointly contributed by concurrent multiple exposures, we also computed the total number (ranging from 0 to 9 ) of physical tasks that involved lower-extremity joint-loading (with sitting excluded).

Participants were asked whether they had ever held a job (including farming and homemaking) that required spending more than $50 \%$ of their time doing each of these activities: light work standing in one place; sitting; heavy work standing in one place; crouching or kneeling; and walking. Participants were also asked 3 questions about heavy lifting: whether they had ever held a job (including farming and homemaking) that required lifting at least $22 \mathrm{lbs}(10 \mathrm{~kg})$, at least $44 \mathrm{lbs}(20 \mathrm{~kg})$, and at least $110 \mathrm{lbs}(50 \mathrm{~kg}), 10$ or more times a week. We compared those who did and did not report doing each of these 8 tasks. The total number of physical tasks, ranging from 0 to 7 , was calculated for those involving lower-extremity joint-loading (sitting excluded).

\section{Other participant characteristics}

These participant characteristics were also included as covariates in multivariable models because research has indicated they are associated with the development of hip and/or knee $\mathrm{OA}^{21-25}$ : age at time of interview, gender, race (Caucasian vs African American), body mass index (BMI) at time of clinic examination (calculated from height measured without 
shoes and weight measured with a balance-beam scale), self-reported smoking (current, ever, or never), and self-reported knee and hip injuries (for analyses of knee and hip OA, respectively) including fractures or other injuries severe enough to require use of a cane, cast, or crutch for 2 weeks or longer. In addition, we included exposure to physically demanding household tasks as a covariate. Data on the association between household activities and knee or hip OA are limited, but it is possible that household demands also increase risk. Participants were asked to indicate whether they had done light or heavy housework, yardwork, or home repairs around the house for more than 1 year. If participants answer positively, they were asked to indicate the frequency with which they engaged in these tasks, with $0=$ never and $4=$ always: walking, lifting, bending, kneeling, crawling, stair-climbing, and doing heavy work while standing. We computed the total number of household tasks each participant indicated performing often or always; this variable was included as a covariate.

\section{Statistical analyses}

We separately examined the associations of knee and hip OA with 3 sets of occupational variables defined above, i.e., the 6 broad industrial groups of the longest job ever held, the 10 specific occupational tasks for the longest job, and lifetime exposure to 8 occupational tasks. The putative associations were examined separately for radiographic and symptomatic OA. We used chi-square tests to compare OA prevalence across broad industrial groups of the longest job ever held, as well as according to each of the specific occupational tasks. We then performed multivariable-adjusted logistic regression models to examine associations of OA with job industrial groups (using the Managerial and Professional Specialty occupations treated as the referent and all other groups included in the same model) and specific occupational tasks. The potential confounders included in these models were age, race, gender, BMI, prior knee or hip injury (as appropriate), and smoking. We also examined interaction terms between gender and occupational variables; these were not statistically significant and therefore not included in final models.

Given the cross-sectional design of these data, study participants' occupation selection or physical task engagement in their longest job might have been influenced by the presence of OA symptoms. To address this potential bias, for the data pertinent to the longest job, we conducted secondary analyses of symptomatic OA, restricting the sample to individuals who reported that their longest job ended before age 50 years. Because there were differences in demographic characteristics between participants who were newly enrolled at this timepoint and those participating in their first followup visit, we also performed sensitivity analyses to examine whether associations between occupational tasks and OA differed between these 2 groups. We conducted analyses separately for each group. No substantial differences were observed between the groups, so we present analyses for the whole sample, for simplicity. We also included a group indicator in multivariable results. This also did not alter associations between occupational tasks and OA, so this was not included in the models presented.

All analyses were performed using SAS PC, Version 9 (SAS Inc., Cary, NC, USA). Statistical significance was evaluated at the $\mathrm{p}<0.05$ level. 


\section{RESULTS}

Table 1 shows demographic characteristics of study participants $(n=2729)$.

\section{Census industrial group of longest job ever held}

A total of 2546 participants (93\%) could be assigned a census industrial group for the longest self-reported job. Of those, the proportions in each industrial group were managerial and professional specialty (22\%); technical, sales, and administrative support (26\%); service $(16 \%)$; farming, forestry, and fishing (2\%); precision production, craft, and repair (12\%); and operators, fabricators, and laborers (23\%).

There was a significant overall difference in the prevalence of radiographic knee OA $(\mathrm{p}<$ $0.001)$, but not radiographic hip OA ( $\mathrm{p}=0.705)$, according to the 6 broad industrial groups (Table 2). In multivariable logistic regression models, however, there were no significant associations of any industrial groups with radiographic knee or hip OA (data not shown).

There was a significant overall difference in the prevalence of symptomatic knee OA, but not symptomatic hip OA, across 6 industrial groups (Table 2). In multivariable logistic regression models, however, there were no significant associations of any industrial groups with symptomatic knee or hip OA.

In the secondary analyses, considering only individuals whose longest job ended before age 50 years, there was also a significant overall difference in the prevalence of symptomatic knee OA, but not symptomatic hip OA, according to industrial groups. Patterns were similar to those shown in Table 2 for the total sample. In multivariable logistic regression models, however, there were no significant associations of any industrial groups with symptomatic knee or hip OA.

\section{Ten specific tasks at longest job ever held}

The mean duration of the longest job reported was 23.0 years (SD 11.3), with mean beginning and ending ages 29.5 years (SD 10.0) and 53.1 years (SD 10.5), respectively.

In bivariate analyses, only sitting and stair-climbing at the longest job ever held were significantly associated with radiographic knee OA (Table 3); no specific tasks at the longest job ever held were associated with radiographic hip OA (Table 4). In multivariable logistic regression models, none of the 10 specific occupational tasks performed at the longest job, nor the cumulative number of these tasks, was significantly associated with radiographic knee or hip OA (Tables 3 and 4).

In bivariate analyses, 6 specific tasks at the longest job ever held were associated with symptomatic knee OA (Table 3) and 4 specific tasks were associated with symptomatic hip OA (Table 4). These tasks were associated with greater odds of symptomatic knee OA in multivariable logistic regression models: walking, lifting > $10 \mathrm{lbs}$, standing, crawling, and doing heavy work while standing, as was the cumulative number of tasks; sitting was associated with lesser odds of symptomatic knee OA (Table 3). These tasks were associated with greater odds of symptomatic hip OA: lifting $>10 \mathrm{lbs}$, bending/twisting/reaching, 
crawling, doing heavy work while standing, as was the cumulative number of tasks (Table $4)$.

In secondary analyses restricted to those whose longest job ended before age $50(n=830)$, the general patterns of association were similar to analyses of the total study sample. However, possibly because of the substantially reduced sample size, the only statistically significant association was between lifting $>10 \mathrm{lbs}$ and symptomatic knee OA (OR 1.56, 95\% CI 1.01-2.42).

\section{Lifetime exposure to jobs involving specific occupational tasks}

In bivariate analyses, only lifetime exposure to sitting was significantly associated with radiographic knee OA (Table 3); there were no significant associations with radiographic hip OA (Table 4). In multivariable logistic regression models, there were no statistically significant associations of lifetime exposures to 8 specific occupational tasks, nor the cumulative number of these tasks, with radiographic knee or hip OA (Tables 3 and 4).

In bivariate analyses, lifetime exposure to 3 specific tasks was significantly associated with symptomatic knee OA (Table 3), and 1 task was associated with symptomatic hip OA (Table 4). In multivariable models, doing heavy work while standing (for more than $50 \%$ of a job) was associated with increased odds of symptomatic knee OA, while sitting for more than $50 \%$ of a job was associated with reduced odds of symptomatic knee OA (Table 3). Doing heavy work while standing (for more than $50 \%$ of a job) and lifting $10 \mathrm{~kg}, 20 \mathrm{~kg}$, or $50 \mathrm{~kg}$ more than 10 times per week was associated with increased odds of symptomatic hip OA; the cumulative number of tasks was also associated with increased odds of symptomatic hip OA (Table 4).

\section{DISCUSSION}

Our study examined associations of a variety of occupational variables with radiographic and symptomatic knee and hip OA in a large community-based cohort. Our analyses showed significant associations of specific occupational task variables with symptomatic knee and hip OA, controlling for demographic factors (age, gender, race), BMI, household tasks, prior injury, and smoking. It is particularly noteworthy that associations between occupational tasks and symptomatic OA persisted when controlling for prior joint injuries, which are known to place individuals at increased risk for OA. These results suggest that mechanisms other than acute joint injuries are involved in the association of physically demanding occupational tasks with symptomatic OA. One possible mechanism is "repetitive use" of joints, but causal pathways have not been found.

Individuals were $30 \%-60 \%$ more likely to have symptomatic knee OA if they engaged in occupational walking, lifting, standing, crawling, and doing heavy work while standing. Also, individuals were significantly less likely to have symptomatic knee OA if they engaged in occupational sitting. Studies have reported significant associations of radiographic and symptomatic knee OA with "blue collar" jobs, as well as with specific occupational tasks similar to those observed in our study, including kneeling, squatting, walking, lifting, and climbing ${ }^{4-6,9,18,19,26}$. Specific tasks related to radiographic and 
symptomatic knee OA have not been entirely consistent across studies. The reported heterogeneity in these associations may be due to differences in the characteristics of study populations, the prevalence of physical exposures, and the sensitivity and specificity of the instruments used to assess occupational tasks. Knee-bending has been most consistently associated with knee $\mathrm{OA}$ in studies ${ }^{3}$. While neither squatting nor crouching/kneeling were significantly associated with symptomatic knee OA in adjusted models in our study, the association of squatting with symptomatic knee OA was nearly statistically significant.

For symptomatic hip OA, we observed significant positive associations with lifting, bending/twisting/reaching, crawling, and doing heavy work while standing, and magnitudes of these associations were also relatively similar. Studies have reported associations of radiographic or symptomatic hip OA with prolonged standing, lifting, and sitting (negative for last association) $)^{8,11,12,15,27}$. Similar to knee OA, associations of radiographic and symptomatic hip OA with specific occupational tasks have not been entirely consistent across studies. However, the strongest and most consistent evidence has been for an overall heavy physical workload and heavy lifting ${ }^{10,28}$. Results of our study provide additional evidence for the associations of these 2 types of occupational exposures with symptomatic hip OA, as all 4 lifting variables and both heavy-work-related variables were associated with greater odds of symptomatic hip OA. Studies have also found a strong association between farming and symptomatic hip $\mathrm{OA}^{8-10,12,29}$. In contrast, we found no relationship between symptomatic hip OA and the industrial group of farming, fishing, and forestry. This may be partly due to the very small proportion of study participants who reported that their longest job was in this category.

Associations of occupational variables with radiographic OA were much weaker than with symptomatic OA, with few statistically significant associations. Most previous studies have examined associations of occupational variables with symptomatic $\mathrm{OA}^{5,9,11,15,18,19,27,29,30}$. However, some research has shown significant associations with radiographic OA, irrespective of symptoms. In the First National Health and Nutrition Examination Survey (NHANES I), greater levels of occupational knee-bending were associated with increased odds of radiographic knee OA among participants age 55-64 years (but not younger participants), and greater overall strength demand of the occupation was associated with increased odds among women age 55-64 years ${ }^{26}$. In the Framingham study, men whose current job involved bending plus medium, heavy, or very heavy demands had about twice the odds of radiographic knee OA (adjusted for age and other factors) compared to those who did no bending and sedentary or light-demand jobs; there was no significant association for women ${ }^{4}$. While these previous studies show some evidence for associations of occupational tasks with radiographic OA, significant associations have been primarily for specific groups (i.e., those age 55 yrs and older) and for more extensive occupational loads. Results of our study support that occupational joint-loading is a stronger predictor of symptomatic disease than of radiographic findings alone.

Several different aspects of occupational exposure were characterized in our study, and we observed some differences in associations of knee and hip OA with these occupational characteristics. The 6 broad job industrial groups pertaining to the longest job ever held were associated with knee $\mathrm{OA}$ in expected patterns but were not significant in adjusted models. In 
general, characterizing broad industrial groups is a limited approach, as these groups can encompass a relatively wide array of jobs with differing occupational tasks. However, studies that have examined more specific job titles, as well as those that have characterized specific physical demands of job categories, have shown significant associations with hip and/or knee $\mathrm{OA}^{4,9,26,29}$.

We assessed specific occupational tasks using 2 different approaches: tasks performed at the longest job and lifetime exposure to tasks performed for more than $50 \%$ of a job. We observed generally similar patterns of association with symptomatic knee and hip OA for tasks that were assessed using both of these methods. These results provide evidence for the utility of these 2 occupational task assessment approaches in studies of OA risk. However, there are advantages and disadvantages to each of these approaches that should be considered. For instance, although tasks performed at the longest job may be relatively easy for individuals to recall, this approach may miss exposures to tasks performed at other jobs that may have differed substantially from the longest job. In this study, the mean length of the longest job was 23 years. However, for other populations with less stable occupations or more job-switching, this approach may be more limited. Assessing lifetime exposure to tasks performed for more than $50 \%$ of the time offers the advantage of comprehensive lifecourse assessment, although recall of earlier jobs may be difficult for some individuals.

There are several limitations to our study. First, the cross-sectional design could introduce bias if participants' occupation selection or physical task engagement in their longest job was influenced by the presence of OA symptoms. However, when we restricted the sample to participants whose longest job ended before age 50, we observed similar patterns of associations as for the full sample; therefore, we did not find evidence for this type of bias. Second, there are potential limitations in the accuracy of self-reported occupational data in general, and the lack of a "gold standard" limits the assessment of specific self-report items. Some studies have compared concordance of self-reported occupational data with objective reference measures, and results vary according to type of occupational variable and activity assessed $^{31-40}$. Of particular relevance to this study, prior research has shown good agreement between self-report and objective data regarding occupational kneeling, squatting, and standing 34,41 . In addition, self-reports of time-consuming or primary work tasks, which are the tasks most likely to affect OA risk, have shown good agreement with objective sources ${ }^{42}$. Third, our study was conducted among a community-based sample of Caucasian and African American rural participants over age 45 years, which may limit the generalizability of findings. The prevalence of symptomatic knee OA in this cohort (23\%) was higher than in some other cohorts, including NHANES III $(12 \%)^{43}$. There are several possible reasons for this difference, which have been described in detail ${ }^{17}$, including a broader symptom definition and longer timeframe for assessing pain in JoCo OA, geographic differences in disease rates, and high prevalence of heavy occupational and everyday physical activity in a rural region. However, it is noteworthy that our results regarding associations of occupations with $\mathrm{OA}$ are largely in concordance with prior studies in other populations. Fourth, occupational questions for the longest job ever held were asked only of participants who ever held a job outside the home or farm for pay for more than 1 year, thus excluding information on individuals whose primary work was within the home or a home-based farm. However, this resulted in exclusion of only about $5 \%$ of the sample, and 
these individuals were still included in analyses of occupational tasks that required $>50 \%$ of time at a given job.

Our study confirms an important association of occupational tasks with symptomatic lower extremity OA. For both symptomatic knee and hip OA, a variety of physically demanding tasks were associated with increased odds, and for hip OA, a particularly strong and consistent association was observed for lifting tasks. While the specific tasks significantly associated with symptomatic hip versus knee OA were not entirely consistent, there were significant or elevated/borderline significant associations of these tasks for both joint groups: walking, lifting, standing, doing heavy work while standing, squatting, crawling, and bending/ twisting/reaching. Further, the odds of both symptomatic hip and knee OA significantly increased with the number of physically demanding occupational tasks performed. In light of accumulating evidence that occupational joint-loading substantially increases risk for both knee and hip OA, efforts are needed to identify methods for reducing this risk among vulnerable groups. While it may not be possible for some individuals to reduce the physical demands of their current occupational responsibilities, there may be other means of reducing OA risk in this group. For example, other studies have shown that individuals who are overweight and also experience high occupational physical demands are at particularly high risk for $\mathrm{OA}^{18}$, and weight loss interventions would be valuable for this group. Other potential areas for intervention include ameliorating muscle strength imbalances and modifying occupational physical activities to protect joints and reduce joint loads. These strategies have not been well tested in this context and are worthy of further examination.

\section{Acknowledgments}

Supported in part by cooperative agreements S043, S1734, and S3486 from the Centers for Disease Control and Prevention/Association of Schools of Public Health; the NIAMS Multipurpose Arthritis and Musculoskeletal Disease Center grant 5-P60-AR30701; and the NIAMS Multidisciplinary Clinical Research Center grant 5 P60 AR49465-03 and NIAMS Arthritis and Immunology Training Grant T-32-AR007416.

\section{References}

1. Zhang Y, Jordan JM. Epidemiology of osteoarthritis. Rheum Dis Clin North Am. 2008; 34:515-29. [PubMed: 18687270]

2. Vignon E, Valat JP, Rossignol M, Avouac B, Rozenberg S, Thoumie P, et al. Osteoarthritis of the knee and hip and activity: a systematic international review and synthesis. Joint Bone Spine. 2006; 73:442-55. [PubMed: 16777458]

3. Maetzel A, Makela M, Hawker G, Bombardier C. Osteoarthritis of the hip and knee and mechanical occupational exposure — a systematic overview of the evidence. J Rheumatol. 1997; 24:1599-607. [PubMed: 9263158]

4. Felson DT, Hannan MT, Naimark A, Berkeley J, Gordon G, Wilson PW, et al. Occupational physical demands, knee bending, and knee osteoarthritis: results from the Framingham study. J Rheumatol. 1991; 18:1587-92. [PubMed: 1765986]

5. Sandmark H, Hogstedt C, Vingard E. Primary osteoarthritis of the knee in men and women as a result of lifelong physical load from work. Scand J Work Environ Health. 2000; 26:20-5. [PubMed: 10744173]

6. Jensen LK, Mikkelsen S, Loft IP, Eenberg W, Bergmann I, Logager V. Radiographic knee osteoarthritis in floorlayers and carpenters. Scand J Work Environ Health. 2000; 26:257-62. [PubMed: 10901119] 
7. Manninen P, Heliovaara M, Riihimaki H, Suomalainen O. Physical workload and the risk of severe knee osteoarthritis. Scand J Work Environ Health. 2002; 28:25-32. [PubMed: 11871849]

8. Croft P, Coggon D, Cruddas M, Cooper C. Osteoarthritis of the hip: an occupational disease in farmers. BMJ. 1992; 304:1269-72. [PubMed: 1606427]

9. Vingard E, Alfredsson L, Goldie I, Hogstedt C. Occupation and osteoarthrosis of the hip and knee: a register-based cohort study. Int J Epidemiol. 1991; 20:1025-31. [PubMed: 1800399]

10. Lievense A, Bierma-Zeinstra A, Verhagen AP, Verhaar J, Koes B. Influence of work on the development of osteoarthritis of the hip: a systematic review. J Rheumatol. 2001; 28:2520-8. [PubMed: 11708427]

11. Roach KE, Persky V, Miles T, Budiman-Mak E. Biomechanical aspects of occupation and osteoarthritis of the hip: a case-control study. J Rheumatol. 1994; 21:2334-40. [PubMed: 7699638]

12. Croft P, Cooper C, Wickham C, Coggon D. Osteoarthritis of the hip and occupational activity. Scand J Work Environ Health. 1992; 18:59-63. [PubMed: 1553513]

13. Jacobsson B, Dalen N, Tjornstrand B. Coxarthrosis and labour. Int Orthop. 1987; 11:311-3. [PubMed: 3440647]

14. Coggon D, Kellingray S, Inskip H, Croft P, Campbell LK, Cooper C. Osteoarthritis of the hip and occupational lifting. Am J Epidemiol. 1998; 147:523-8. [PubMed: 9521178]

15. Lau EC, Cooper C, Lam D, Chan VN, Tsang KK, Sham A. Factors associated with osteoarthritis of the hip and knee in Hong Kong Chinese: obesity, joint injury, and occupational activities. Am J Epidemiol. 2000; 152:855-62. [PubMed: 11085397]

16. Yoshimura N, Nishioka S, Kinoshita H, Hori N, Nishioka T, Ryujin M, et al. Risk factors for knee osteoarthritis in Japanese women: heavy weight, previous joint injuries, and occupational activities. J Rheumatol. 2004; 31:157-62. [PubMed: 14705235]

17. Jordan JM, Helmick CG, Renner JB, Luta G, Dragomir AD, Woodard J, et al. Prevalence of knee symptoms and radiographic and symptomatic knee osteoarthritis in African Americans and Caucasians: the Johnston County Osteoarthritis Project. J Rheumatol. 2007; 31:172-80. [PubMed: 17216685]

18. Coggon D, Croft JB, Kellingray S, Barrett D, McLaren M, Cooper C. Occupational physical activities and osteoarthritis of the knee. Arthritis Rheum. 2000; 43:1443-9. [PubMed: 10902744]

19. Cooper C, McAlindon T, Coggon D, Egger P, Dieppe P. Occupational activity and osteoarthritis of the knee. Ann Rheum Dis. 1994; 53:90-3. [PubMed: 8129467]

20. US Bureau of Labor Statistics. Census Industrial and Occupational Classification Codes. Internet. 1990. www.bls.gov/nls/guex/r1/497r1cbka1.pdf

21. Allen KD, Helmick CG, Schwartz TA, DeVellis B, Renner JB, Jordan JM. Racial differences in self-reported pain and function among individuals with radiographic hip and knee osteoarthritis: The Johnston County Osteoarthritis Project. Osteoarthritis Cartilage. 2009; 17:1132-6. [PubMed: 19327733]

22. Abbate LM, Stevens J, Schwartz TA, Renner JB, Helmick CG, Jordan JM. Anthropometric measures, body composition, body fat distribution, and knee osteoarthritis in women. Obesity. 2006; 14:1274-81. [PubMed: 16899809]

23. Felson DT, Zhang Y, Hannan MT, Naimark A, Weissman B, Aliabadi P, et al. Risk factors for incident radiographic knee osteoarthritis in the elderly: the Framingham Study. Arthritis Rheum. 1997; 40:728-33. [PubMed: 9125257]

24. Lohmander LS, Eglund MP, Dahl LL, Roos EM. The long-term consequence of anterior cruciate ligament and meniscus injuries: osteoarthritis. Am J Sports Med. 2007; 35:1756-69. [PubMed: 17761605]

25. Cooper C, Inskip H, Croft P, Campbell L, Smith G, McLaren M, et al. Individual risk factors for hip osteoarthritis: obesity, hip injury, and physical activity. Am J Epidemiol. 1998; 147:516-22. [PubMed: 9521177]

26. Anderson JJ, Felson DT. Factors associated with osteoarthritis of the knee in the first national Health and Nutrition Examination Survey (HANES I). Am J Epidemiol. 1988; 128:179-89. [PubMed: 3381825] 
27. Yoshimura N, Sasaki S, Iwasaki K, Danjoh S, Kinoshita H, Yasuda T, et al. Occupational lifting is associated with hip osteoarthritis: a Japanese case-control study. J Rheumatol. 2000; 27:434-40. [PubMed: 10685811]

28. Juhakoski R, Heliovaara M, Impivaara O, Kroger H, Knekt P, Lauren H, et al. Risk factors for the development of hip osteoarthritis: a population-based prospective study. Rheumatology. 2009; 48:83-7. [PubMed: 19056801]

29. Rossignol M, Leclerc A, Allaert FA, Rozenberg S, Valat JP, Avouac B, et al. Primary osteoarthritis of hip, knee, and hand in relation to occupational exposure. Occup Environ Med. 2005; 62:772-7. [PubMed: 16234403]

30. Rossignol M, Leclerc A, Hilliquin P, Allaert FA, Rozenberg S, Valat JP, et al. Primary osteoarthritis and occupations: a national cross sectional survey of 10412 symptomatic patients. Occup Environ Med. 2003; 60:882-6. [PubMed: 14573720]

31. Smith TC, Jacobson IG, Smith B, Hooper TI, Ryan MA, Team FT. For the Millennium Cohort Study Team. The occupational role of women in the military service: Validation of occupation and prevalence of exposures in the Millennium Cohort Study. Int J Environ Health Res. 2007; 17:27184. [PubMed: 17613091]

32. Baumgarten M, Siemiatycki J, Gibbs BW. Validity of work histories obtained by interview for epidemiologic purposes. Am J Epidemiol. 1983; 118:583-91. [PubMed: 6637985]

33. Burdorf A, Laan J. Comparison of methods for the assessment of postural load on the back. Scand J Work Environ Health. 1991; 17:425-9. [PubMed: 1838618]

34. Pope DP, Silman AJ, Cherry NM, Pritchard C, Macfarlane GJ. Validity of a self-completed questionnaire measuring the physical demands of work. Scand J Work Environ Health. 1998; 24:376-85. [PubMed: 9869309]

35. Viikari-Juntura E, Rauas S, Mrtikainen R, Kuosma E, Riihimaki H, Takala E, et al. Validity of self-reported physical work load in epidemiological studies on musculoskeletal disorders. Scand J Work Environ Health. 1996; 22:251-9. [PubMed: 8881013]

36. Wiktorin C, Vingard E, Mortimer M, Pernold G, Wigaeus-Hjelm E, Kilbom A, et al. Interview versus questionnaire for assessing physical loads in the population-based MUSIC-Norrtalje Study. Am J Ind Med. 1999; 35:441-55. [PubMed: 10212697]

37. Wiktorin C, Karlqvist L, Winkel J. Stockholm MUSIC I Study Group. Validity of self-reported exposures to work postures and manual materials handling. Scand J Work Environ Health. 1993; 19:208-14. [PubMed: 8367699]

38. Bourbonnais R, Meyer F, Theriault G. Validity of self reported work history. Brit J Ind Med. 1988; 45:29-32. [PubMed: 3342185]

39. Bond GG, Bodner KM, Sobel W, Shellenberger RJ, Flores GH. Validation of work histories obtained from interviews. Am J Epidemiol. 1988; 128:343-51. [PubMed: 3256301]

40. Stewart WF, Tonascia JA, Matanoski GM. The validity of questionnaire-reported work history in live respondents. J Occup Med. 1987; 29:795-800. [PubMed: 3681489]

41. Andrews DM, Norman RW, Wells RP, Neumann P. Comparison of self-report and observer methods for repetitive posture and load assessment. Occup Ergonomics. 1998; 1:211-22.

42. Unge J, Hansson G, Ohlsson K, Nordander C, Axmon A, Winkel J, et al. Validity of self-assessed reports of occurrence and duration of occupational tasks. Ergonomics. 2005; 48:12-24. [PubMed: 15764303]

43. Dillon CF, Rasch EK, Gu Q, Hirsch R. Prevalence of knee osteoarthritis in the United States: arthritis data from the Third National Health and Nutrition Examination Survey 1991-1994. J Rheumatol. 2006; 33:2271-9. [PubMed: 17013996] 


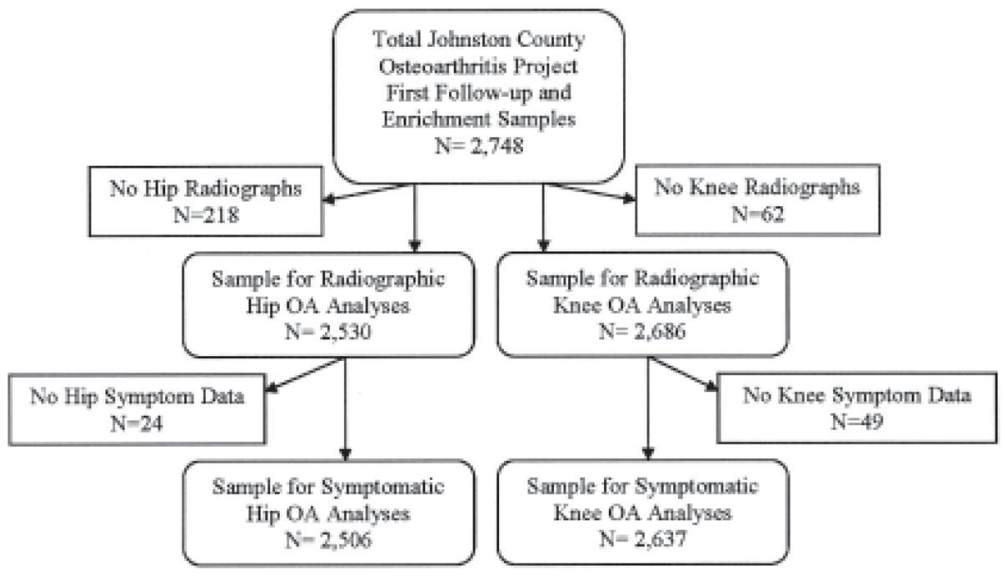

Figure 1.

Numbers of participants in study analyses of specific outcomes of radiographic and symptomatic knee and hip osteoarthritis (OA). 


\section{Table 1}

Characteristics of study sample, including participants with hip and/or knee radiographs.

\begin{tabular}{|c|c|c|c|}
\hline & Total Sample, $(\mathrm{n}=\mathbf{2 7 2 9})$ & $\operatorname{Men}(\mathbf{n}=933)$ & Women $(n=1796)$ \\
\hline Mean age (SD), yrs & $63.6(10.5)$ & $63.3(9.6)$ & $63.8(10.8)$ \\
\hline N (\%) African American & $885(33.1)$ & $269(29.3)$ & $616(35.0)$ \\
\hline Mean BMI (SD) & $30.7(3.7)$ & $29.8(5.6)$ & $31.1(7.2)$ \\
\hline \multicolumn{4}{|l|}{ Smoking } \\
\hline $\mathrm{N}(\%)$ current smokers & $437(17.0)$ & $194(22.6)$ & $243(14.3)$ \\
\hline $\mathrm{N}(\%)$ former smokers & $706(27.6)$ & $326(37.9)$ & $380(22.3)$ \\
\hline $\mathrm{N}(\%)$ with prior hip injury & $85(3.2)$ & $36(4.0)$ & $49(2.8)$ \\
\hline $\mathrm{N}(\%)$ with prior knee injury & $278(10.6)$ & $109(11.9)$ & $169(9.8)$ \\
\hline $\mathrm{N}(\%)$ with radiographic knee $\mathrm{OA}^{*}$ & $927(34.5)$ & $317(34.2)$ & $610(34.7)$ \\
\hline $\mathrm{N}(\%)$ with symptomatic knee OA ${ }^{* *}$ & $592(22.5)$ & $189(20.6)$ & $403(23.4)$ \\
\hline $\mathrm{N}(\%)$ with radiographic hip $\mathrm{OA}^{\dagger}$ & $847(33.2)$ & $303(33.3)$ & $544(33.6)$ \\
\hline $\mathrm{N}(\%)$ with symptomatic hip $\mathrm{OA}^{\dagger \dagger}$ & $294(11.7)$ & $92(10.2)$ & $202(12.6)$ \\
\hline \multicolumn{4}{|c|}{ From 2686 participants with knee radiographs. } \\
\hline \multicolumn{4}{|c|}{ From 2637 participants with knee radiographs and data on knee symptoms. } \\
\hline
\end{tabular}


Table 2

Prevalence of knee and hip OA, by census industrial group of longest job ever held.

\begin{tabular}{lcccc}
\hline & $\begin{array}{c}\text { N (\%) with } \\
\text { Radiographic Knee } \\
\mathbf{O A}^{*}\end{array}$ & $\begin{array}{c}\mathbf{N}(\%) \text { with } \\
\text { Symptomatic Knee } \\
\mathbf{O A}^{*}\end{array}$ & $\begin{array}{c}\mathbf{N}(\%) \text { with } \\
\text { Radiographic Hip OA }\end{array}$ & $\begin{array}{c}\text { N (\%) with } \\
\text { Symptomatic Hip OA }\end{array}$ \\
\hline $\begin{array}{l}\text { Managerial and professional } \\
\text { specialty }\end{array}$ & $155(28.7)$ & $85(16.0)$ & $170(33.2)$ & $51(10.0)$ \\
$\begin{array}{l}\text { Technical, sales, and } \\
\text { administrative support }\end{array}$ & $188(28.9)$ & $121(18.9)$ & $190(31.6)$ & $60(10.0)$ \\
$\begin{array}{l}\text { Service } \\
\text { Farming, forestry, and fishing }\end{array}$ & $164(41.3)$ & $118(30.1)$ & $118(33.0)$ & $43(12.0)$ \\
$\begin{array}{l}\text { Precision production, craft, and } \\
\text { repair }\end{array}$ & $18(47.4)$ & $8(22.9)$ & $17(44.7)$ & $3(8.3)$ \\
$\begin{array}{l}\text { Operators, fabricators, and } \\
\text { laborers }\end{array}$ & $118(37.2)$ & $78(24.8)$ & $99(32.1)$ & $38(12.3)$ \\
\hline
\end{tabular}

* Overall chi-square test significant $(\mathrm{p}<0.001)$. OA: osteoarthritis. 


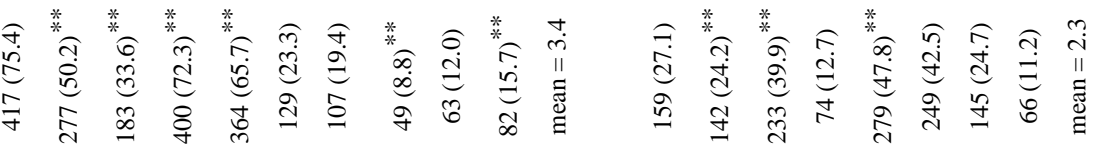

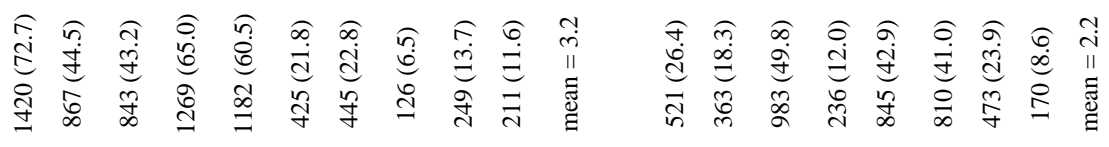

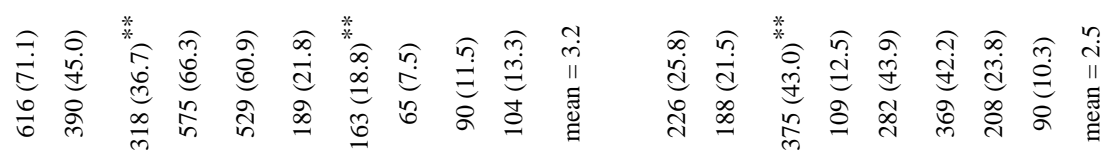

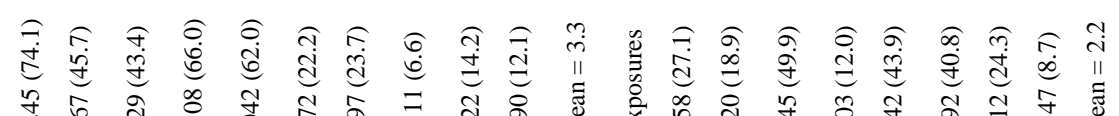

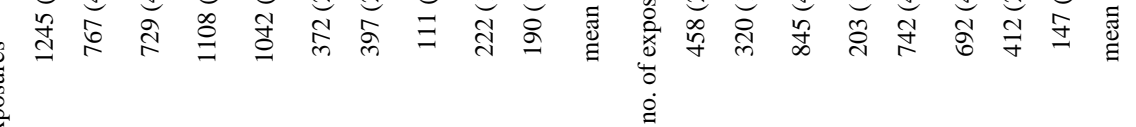

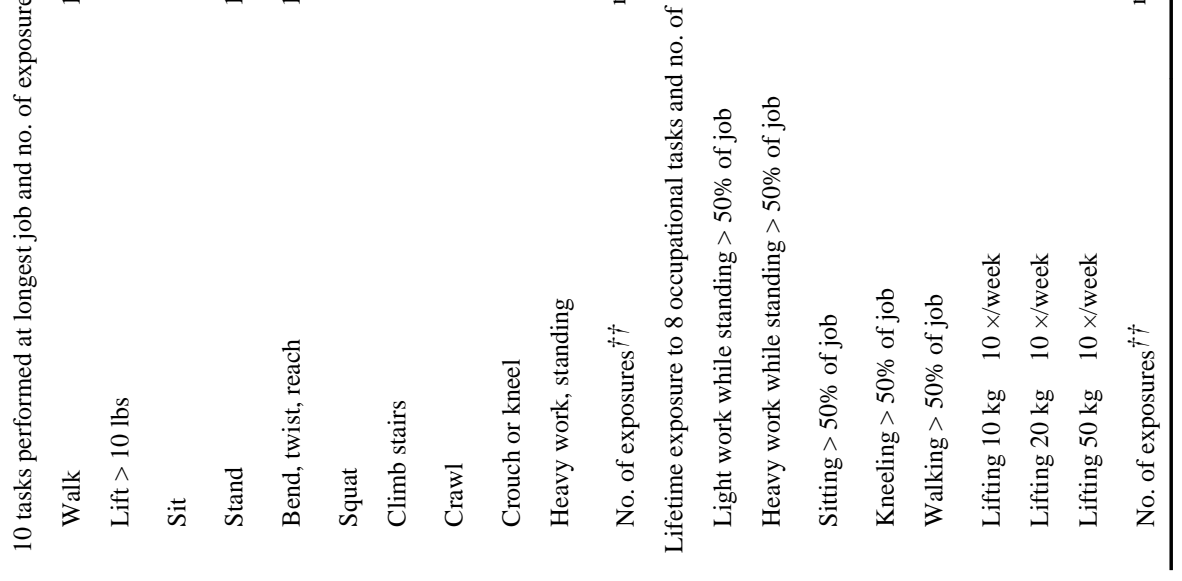

8 


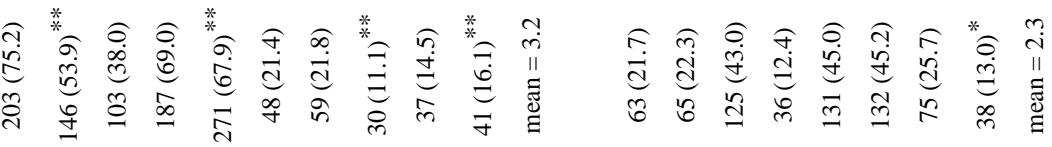

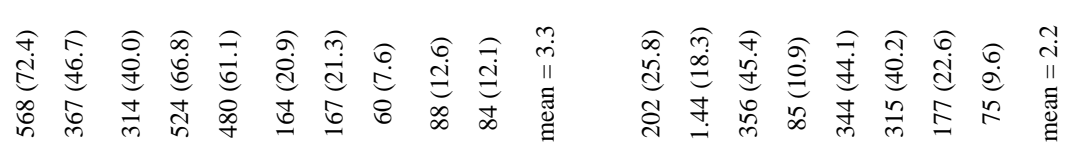

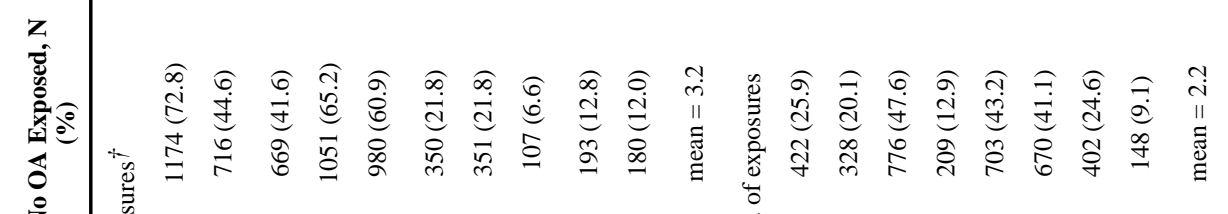


